\title{
Laboratory Performance Evaluation of High Modulus Asphalt Concrete Modified with Different Additives
}

\author{
Peng Li, ${ }^{1}$ Mulian Zheng, ${ }^{1}$ Fei Wang, ${ }^{2}$ Fa Che, ${ }^{3}$ Hongyin Li, ${ }^{4}$ \\ Qinglei $\mathrm{Ma}^{5}$ and Yonghong Wang ${ }^{6}$ \\ ${ }^{1}$ Key Laboratory for Special Area Highway Engineering of Ministry of Education, Chang'an University, \\ South Erhuan Middle Section, Xian, Shaanxi 710064, China \\ ${ }^{2}$ Henan Transportation Research Institute Co., Ltd., Hanghaizhong Road, Zhengzhou, Henan 0371, China \\ ${ }^{3}$ Highway Administration of Bureau Zibo City, East Gongqingtuan Road, Zhangdian District, Zibo, Shandong 255038, China \\ ${ }^{4}$ Shandong Highway Administration Bureau, Shungeng Road, Jinan, Shandong 0531, China \\ ${ }^{5}$ Shandong Highway Engineering Institute, East Jingshi Road, Jinan City, Shandong 26777, China \\ ${ }^{6}$ Transportation Administration Bureau of Xianning City, Xianning Road, Wenquan District, Hubei 0715, China
}

Correspondence should be addressed to Mulian Zheng; zhengml@chd.edu.cn

Received 24 January 2017; Accepted 24 April 2017; Published 21 May 2017

Academic Editor: Meor Othman Hamzah

Copyright (C) 2017 Peng Li et al. This is an open access article distributed under the Creative Commons Attribution License, which permits unrestricted use, distribution, and reproduction in any medium, provided the original work is properly cited.

\begin{abstract}
The objective of this study is to evaluate comprehensive performance of high modulus asphalt concrete (HMAC) and propose common values for establishing evaluation system. Three gradations with different modifiers were conducted to study the high and low temperature performance, shearing behavior, and water stability. The laboratory tests for HMAC included static and dynamic modulus tests, rutting test, uniaxial penetration test, bending test, and immersion Marshall test. Dynamic modulus test results showed that modifier can improve the static modulus and the improvements were remarkable at higher temperature. Moreover, modulus of HMAC-20 was better than those of HMAC-16 and HMAC-25. The results of performance test indicated that HMAC has good performance to resist high temperature rutting, and the resistances of the HMAC-20 and HMAC-25 against rutting were better than that of HMAC-16. Then, the common values of dynamic stability were recommended. Furthermore, common values of HMAC performance were established based on pavement performance tests.
\end{abstract}

\section{Introduction}

High modulus asphalt concrete (HMAC) is one of attracting alternatives to enhance load-bearing capacity of pavement structure against conventional structural distresses, such as rutting and fatigue crack [1]. Rutting resistance of conventional mixture is improved by adding special additives such as antirutting additive or using hard grade asphalt binder in the mixture [2]. One of the most controversial issues concerning HMAC is systematic performance evaluation. Many researches have been conducted regarding high and low temperature performance and water stability. Lee et al. evaluated the high temperature performance and fatigue performance of HMAC based on dynamic modulus, moisture susceptibility, wheel tracking, and fatigue tests [3]. Geng et al. studied stiffness, elastic recovery, workability, and thermal cracking resistance of HMAC and found that the asphalt layers thickness could be significantly reduced by replacing neat binder with HMABs. [4]. Espersson studied dynamic modulus of HMAC at different temperatures to obtain the reduction in thickness depending on the temperature and the use of HMAC, getting that HMAC and conventional bitumen behaved differently in terms of stiffness and elasticity. HMAC in the study had higher complex modulus at all the evaluated temperatures and viscosity was also higher [5]. Laboratory tests, including dynamic modulus, creep compliance, fatigue, moisture damage, and rutting, were conducted to evaluate the performance of different types of WMA mixes [6]. Han chose two kinds of aggregates (basalt and limestone) with obvious differences to study the impact of aggregates on the high modulus mixture properties of hard asphalt (such as high temperature properties, modulus, and fatigue resistance), 
TABLE 1: Properties of Zhonghai A-70 asphalt.

\begin{tabular}{lc}
\hline Test indexes & Measured value \\
\hline Penetration $(1 / 10 \mathrm{~mm}) 100 \mathrm{~g}, 25^{\circ} \mathrm{C}, 5 \mathrm{~S}$ & 67 \\
Penetration index & -0.7 \\
Ductility $(\mathrm{cm}), 10^{\circ} \mathrm{C}$ & 23 \\
Ductility $(\mathrm{cm}), 15^{\circ} \mathrm{C}$ & 104 \\
Softening point $\left({ }^{\circ} \mathrm{C}\right)$ & 48 \\
Dynamic viscosity $(\mathrm{Pa} / \mathrm{s}), 60^{\circ} \mathrm{C}$ & 183 \\
Wax content $(\%)$ & 2 \\
Flash point $\left({ }^{\circ} \mathrm{C}\right)$ & 276 \\
Solubility $(\%)$ & 99.8 \\
Density $\left(\mathrm{g} / \mathrm{cm}^{3}\right), 15^{\circ} \mathrm{C}$ & 1.0029 \\
TFOT & \\
$\quad$ Quality change $(\%)$ & 0.1 \\
Residual penetration ratio $(\%)$ & 64 \\
Residual ductility $10^{\circ} \mathrm{C}(\mathrm{cm})$ & 10 \\
$\quad$ Residual ductility $15^{\circ} \mathrm{C}(\mathrm{cm})$ & 17 \\
\hline
\end{tabular}

showing that a balanced design of high temperature performance, modulus, and fatigue resistance properties can be achieved on the mixture thronging the gradation and the hard asphalt dosage adjustment, for different properties aggregate [7]. Wu et al. evaluated performance of several kinds of additives for high modulus asphalt mixture by tests. The testing results in the article had proved that the existing China-made additives can also meet the requirement of high modulus asphalt concrete (HMAC) [8]. Sun and Li tested fatigue properties of high modulus asphalt using Dynamic Shear Rheometer (DSR) and showing that the fatigue performance of PR-Plasts is better than rock asphalt and $15 / 25 \#$ is the worst at given conditions [9]. However, little research results have been reported concerning static and dynamic modulus at different temperatures, relation of static and dynamic modulus, and reasonable evaluation indicators of rut. In addition, research about common values for HMAC performances should be recommended, and then comprehensive performance evaluation system of HMAC needs to be further conducted from performance test $[2-5,7]$.

Performance tests (including static modulus and dynamic modulus, high and low temperature, water stability, and shear behavior tests) were conducted on three different mixtures (HMAC-16, HMAC-20, and HMAC-25) in this study and the test temperatures were 15,20 , and $60^{\circ} \mathrm{C}$. Based on the performance tests, common values of HMAC were proposed which can be a reference for establishing evaluation system of HMAC performance.

\section{Materials and Test Scheme}

\subsection{Materials}

2.1.1. Asphalt and Aggregate. In this study, Zhonghai A-70 asphalt with high consistency and viscosity at $60^{\circ} \mathrm{C}$ was chosen to ensure the resistance to permanent deformation. The physical and mechanical features of the asphalt are shown in Table 1.
Rutting resistance of HMAC is affected by the shape and interlock of aggregates. Therefore, clean, hard, wearresistant, crushed, and nonacidic aggregates were selected in this study to achieve high rutting resistance of asphalt mixtures. Limestone was employed as aggregate. Three types of asphalt mixtures known as HMAC-16, HMAC-20, and HMAC-25 were studied. The gradations of HMAC-16 were chosen following the JTG F40-2004. Different sizes of coarse aggregate were naturally filled, tamped, compacted, and detected by maximum skeleton strength (CBR) test, in order to get the minimum VCA (voids in coarse aggregates), CBR, and best proportion of each single particle size of coarse aggregate for HMAC-20 and HMAC-25. Talbol formula was adopted to guide the design for fine aggregate gradation and the mass ratio of fine aggregates with different size was determined. Talbol formula is one of the grading formulas and is used to design the grading curve of aggregate, showing the fluctuation range of gradation. The detailed formula is as follows:

$$
P=100\left(\frac{d}{D}\right)^{n}
$$

where $P$ is passing percentage of aggregate, \%, $d$ is mesh size of particles, $\mathrm{mm}, D$ is the maximum particle size of aggregate, $\mathrm{mm}$, and $n$ is grading index.

The gradations of HMAC-20 and HMAC-25 were determined after optimization [10, 11]. Aggregate gradations and optimum bitumen-aggregate ratio are shown in Tables 2 and 3.

2.1.2. Additives. Pavement deformation under the vehicle load is reduced by increasing the modulus of asphalt concrete, which means the rutting resistance is improved. The high modulus additive, antirutting additive, and hard asphalt can be used as additives to increase the modulus of asphalt concrete. In this paper, PR-Module (PRM), PR-Plasts (PRS), and Resin Alloy (RA) additives were adopted, and Zengqiang (ZQ) additive was for contrastive study.

PRM and PRS additives, originated in France, were applied to pavement structure of heavy traffic as shown in Figures 1(a) and 1(b). RA was asphalt compound modifier used as antirutting agent and had stability properties as shown in Figure 1(c). ZQ additive [12], originated in China, was a high modulus additive aimed at reducing rutting, as shown in Figure 1(d). The additives were used according to dry process, meaning that additive was dry-mixed with hot aggregate and then fixed with asphalt.

Mass ratio between additives (PRS, PRM, ZQ, and RA) and matrix asphalt is $0.7 \%, 0.4 \%, 0.8 \%$, and $0.4 \%$, respectively. The main characteristics of these materials are shown in Table 4.

\subsection{Laboratory Testing}

2.2.1. Static Modulus Test. Modulus is the main structural design parameter due to its prominent influence on the deformation of asphalt pavement. The uniaxial compression test was conducted in the universal material testing machine 
TABLE 2: Aggregate gradations of HMAC.

\begin{tabular}{lcccccccccccc}
\hline \multirow{2}{*}{ Sieves $(\mathrm{mm})$} & \multicolumn{10}{c}{ Percent passing (\%) } \\
& 26.5 & 19 & 16 & 13.2 & 9.5 & 4.75 & 2.36 & 1.18 & 0.6 & 0.3 & 0.15 & 0.075 \\
\hline HMAC-16 & 100 & 100 & 93.2 & 82.9 & 70.4 & 39.7 & 27.3 & 21.4 & 15.8 & 11.4 & 8.8 \\
HMAC-20 & 100 & 95.3 & 85.6 & 73.3 & 59.1 & 39.1 & 28 & 21.9 & 16.1 & 11.6 & 9.1 & 6.2 \\
HMAC-25 & 97.3 & 82.2 & 73.4 & 64.9 & 55 & 31.8 & 22.3 & 17.7 & 13.3 & 9.9 & 8 & 5.6 \\
\hline
\end{tabular}

TABLE 3: Optimum bitumen-aggregate ratio of mixtures.

\begin{tabular}{lcccc}
\hline \multirow{2}{*}{ Asphalt Mixture } & \multicolumn{4}{c}{ Optimum bitumen-aggregate ratio (\%) } \\
& Matrix asphalt mix & Mixture with PRM-Module & Mixture with PR-Plasts & Mixture with ZQ \\
\hline HMAC-16 & 4.5 & 4.7 & 4.8 & 4.7 \\
HMAC-20 & 4.2 & 4.4 & 4.3 & 4.4 \\
HMAC-25 & 3.9 & 4.1 & 4.1 & 4.2 \\
\hline
\end{tabular}

TABLE 4: Additives properties.

\begin{tabular}{lccccc}
\hline Materials & Appearance & Size $(\mathrm{mm})$ & Melting point $\left({ }^{\circ} \mathrm{C}\right)$ & Density $\left(\mathrm{g} / \mathrm{cm}^{3}\right)$ & Ingredient \\
\hline PRM & Grey & 5 & 175 & $0.93 \sim 0.965$ & - \\
PRS & Cylinder black & $2 \sim 4$ & $140 \sim 150$ & $0.91 \sim 0.965$ & Plastic $>95 \%$, filling $<5 \%$ \\
RA & Granular black & $2 \sim 4$ & 150 & 0.96 & Rock asphalt, low density polyethylene \\
ZQ & Black solid & 3 & $\geq 160$ & $1 \sim 1.2$ & - \\
\hline
\end{tabular}

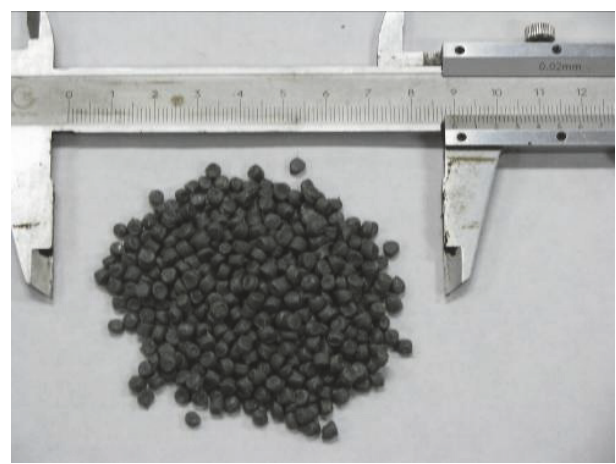

(a) PRM particle



(c) RA particle

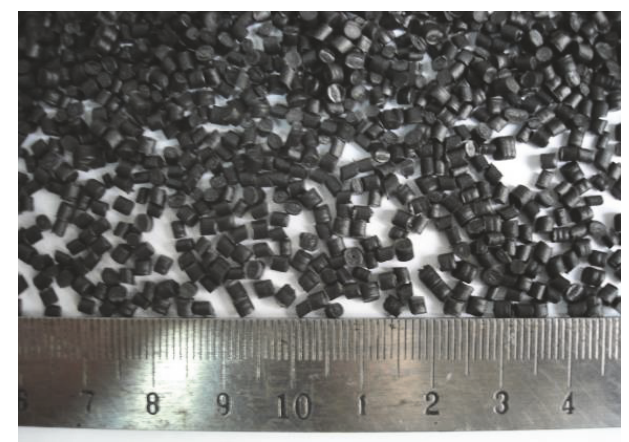

(b) PRS particle



(d) ZQ particle

Figure 1 
TABLE 5: Static modulus test scheme.

\begin{tabular}{lc}
\hline Parameter type & Parameter values \\
\hline Additive & PRM, PRS, RA, and base asphalt \\
Gradation & HMAC-16, HMAC-20, and HMAC-25 \\
Asphalt & A-70 \\
Aggregate & Limestone \\
Asphalt-aggregate ratio & Determined by Marshall test \\
Bulk density & Determined by Marshall test \\
Temperature & 15,20 , and $60^{\circ} \mathrm{C}$ \\
Loading rate & 2 mm $/$ min \\
Loading method & First, determine the compressive strength $(P)$ and then stepping loading \\
Compressive strength test & Failure load \\
Compression resilient modulus test & Compression resilient modulus \\
\hline
\end{tabular}

at $20^{\circ} \mathrm{C}$ and a test rate of $2 \mathrm{~mm} / \mathrm{min}$ was applied to the $100 \mathrm{~mm}$ $\times 100 \mathrm{~mm} \times 100 \mathrm{~mm}$ cylinder specimens (HMAC-16, HMAC20, and HMAC-25) according to ASTM D1074. The additives (PRM, PRS, and RA) were also used to modify the mechanical properties of conventional asphalt mixture [13, 14]. Details of the testing scheme are shown in Table 5.

2.2.2. Dynamic Modulus Test (DMT). The dynamic modulus test was evaluated according to the test procedure described in ASTM D3497-79. Dynamic modulus test was conducted in the simple performance tester at three different temperatures $\left(15,20\right.$, and $\left.60^{\circ} \mathrm{C}\right)$. At each temperature, the test was performed at eight different frequencies $(25,10,5,1,0.5,0.2$, 0.1 , and $0.01 \mathrm{~Hz}$ ). The tests specimens used in the dynamic modulus tests were directly obtained from the gyratory compactor with a diameter of $100 \mathrm{~mm}$ and height of $150 \mathrm{~mm}$ as depicted in Figures 2(a) and 2(b).

\subsubsection{Wheel Tracking Test}

(1) Conventional Wheel Tracking Test. The conventional wheel tracking test was conducted to evaluate the high temperature stability of asphalt mixtures. A contact pressure of $700 \mathrm{kPa}$ was applied to the $300 \mathrm{~mm} \times 300 \mathrm{~mm} \times 50 \mathrm{~mm}$ slab specimens at $60^{\circ} \mathrm{C}$ according to the test procedure described in JTJ T0719.

(2) Unconventional Wheel Tracking Test. Contact pressures $(800,900$, and $1000 \mathrm{kPa})$ were applied to the $300 \mathrm{~mm} \times$ $300 \mathrm{~mm} \times 50 \mathrm{~mm}$ slab specimens, respectively. The unconventional wheel tracking tests were conducted at $70^{\circ} \mathrm{C}$ to evaluate the permanent deformation characteristics of asphalt mixtures.

2.2.4. Uniaxial Penetration Test. The uniaxial penetration test is similar to the CBR test in soil test method. A cylindrical steel pressure head was loaded on a cylinder specimen at a fixed loading rate, to simulate the actual stress state of the road. In this study, the uniaxial penetration method was used for evaluating the shear performance of asphalt mixture.

The uniaxial penetration test was conducted to evaluate the shear behavior of asphalt mixtures according to the test procedure described in JTGE40-2007-T0134. A test rate of $1 \mathrm{~mm} / \mathrm{min}$ as well as head size of $28.5 \mathrm{~mm}$ was applied to the $100 \mathrm{~mm} \times 100 \mathrm{~mm}$ cylinder specimens at three different temperatures $\left(15,20\right.$, and $\left.60^{\circ} \mathrm{C}\right)$. During the constant temperature process, the temperature will be controlled automatically by the temperature controller with heat preservation for at least $6 \mathrm{~h}$. Figure 3 shows the test instruments and specimen of uniaxial penetration test.

2.2.5. Bending Test at Low Temperature. The bending test was conducted according to the test procedure described in JTJ T0715-2011 to evaluate the low temperature performance of asphalt mixtures. A test rate of $50 \mathrm{~mm} / \mathrm{min}$ was applied to the $250 \mathrm{~mm} \times 30 \mathrm{~mm} \times 35 \mathrm{~mm}$ slab specimens at temperature of $-10^{\circ} \mathrm{C}$.

2.2.6. Water Stability Test. Freeze-thaw splitting strength test and immersion Marshall test were conducted to study the water stability of mixture after freeze-thaw cycles on specimens. Three groups of specimens (HMAC-16, HMAC-20, and HMAC-25) were compacted in a Marshall compactor according to the test procedure described in JTJ T0709-2011 and AASHTO T-283-98.

Marshall samples were first water-conditioned by vacuum saturation for 15 minutes with distilled water, then were placed in water under atmospheric pressure for 0.5 hours, and finally subjected to successive cycles of freezing and thawing. Each cycle consisted of freezing at $-20^{\circ} \mathrm{C}$ for 16 hours followed by soaking in distilled water at $60^{\circ} \mathrm{C}$ for 24 hours [13-16].

\section{Results and Discussion}

\subsection{Modulus}

3.1.1. Static Modulus. Modulus of asphalt mixture, the main indicator characterizing antideformation performance of HMAC, is the key parameter of comprehensive evaluation system. Details of the static compressive modulus test are shown in Figures 4(a)-4(c). 


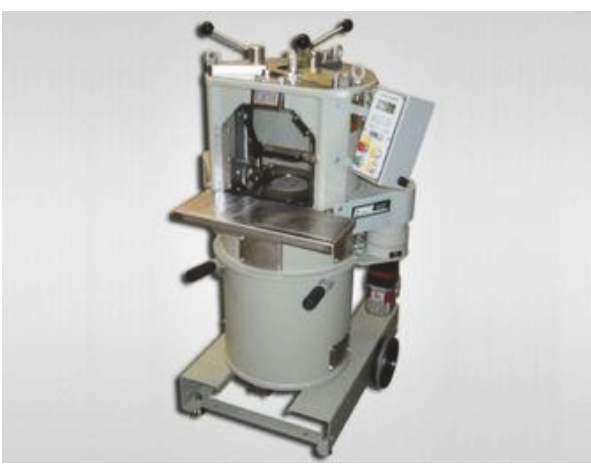

(a) Gyratory compactor

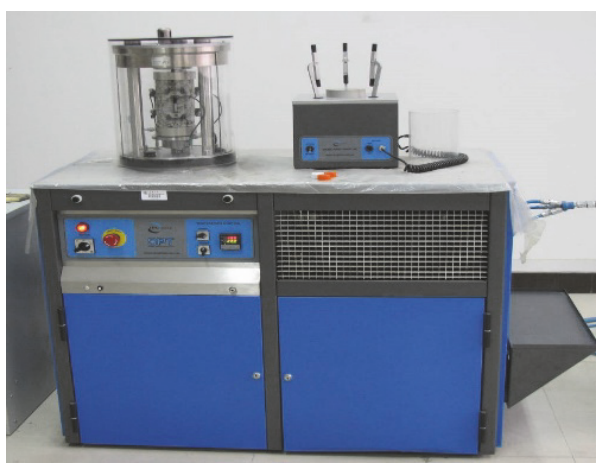

(b) Simple performance tester

Figure 2

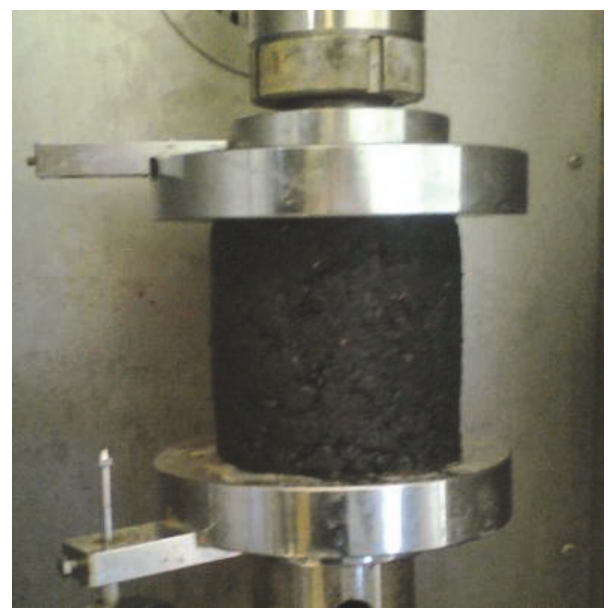

Figure 3: Uniaxial penetration test.

(1) The Effect of Temperature on Modulus. Static modulus of asphalt mixture decreased when the temperature increased from $15^{\circ} \mathrm{C}$ to $60^{\circ} \mathrm{C}$, meaning that asphalt mixture is sensitive to temperature. Compressive moduli of HMAC at 15, 20, and $60^{\circ} \mathrm{C}$ were $46 \%, 58 \%$, and $72 \%$ more than those of conventional mixture, and the improving effect was more striking with the increasing temperature.

Figure 4 shows that compressive modulus of asphalt mixture decreases with the increase of temperature. Asphalt mixture is a typical complex viscoelastic plasticity indicating that the mechanical properties are very sensitive to temperature. Along with the increase of temperature, the physical characteristics manifest as being soft whereas strength and stiffness decrease resulting in the decrease of modulus.

In general, the high temperature stability of asphalt mixture increases along with increase of modulus. At the temperature of 15,20 , and $60^{\circ} \mathrm{C}$, compressive moduli of high modulus asphalt concrete are 1.3 1.5, 1.4 1.6, and 1.8 2.1 times the value of matrix asphalt mixture, respectively. The following can be indicated: compressive moduli of high modulus asphalt concrete are far bigger than that of ordinary asphalt mixture, and the higher the temperature, the more apparent the improving effect.
At the temperature of 15,20 , and $60^{\circ} \mathrm{C}$, moduli of HMACPRM were $13 \% \sim 18 \%, 1 \% \sim 7 \%$, and $4 \% \sim 7 \%$ bigger than those of HMAC-PRS and moduli of HMAC-PRS were $4 \%$ $7 \%, 10 \% \sim 20 \%$, and 4\% 7\% greater than that of HMAC-RA, respectively, which means that PRM has the most significant effect on improving modulus of asphalt mixture. The ranking among the three mixes is HMAC-PRM, HMAC-RA, and HMAC-PRS from superior to inferior.

(2) The Effect of Nominal Maximum Aggregate Size on Modulus. The compressive moduli of HMAC-16 were 2300 $2900 \mathrm{MPa}, 1600 \sim 2000 \mathrm{MPa}$, and 490 560 MPa at the temperature of 15,20 , and $60^{\circ} \mathrm{C}$, and those of HMAC-20 were 2600 $3300 \mathrm{MPa}, 1700 \sim 2300 \mathrm{MPa}$, and $520 \sim 610 \mathrm{MPa}$ and those for HMAC-25 were 2200 2900 MPa, 1500 2000 MPa, and 490 $590 \mathrm{MPa}$, respectively. On the whole, the modulus of HMAC20 was bigger than those of HMAC-16 and HMAC-25.

Generally speaking, static moduli of HMAC-16 are better than those of HMAC-25 and HMAC-20. However, results obtained from $15^{\circ} \mathrm{C}, 20^{\circ} \mathrm{C}$, and $60^{\circ} \mathrm{C}$ showed that static modulus of HMAC-20 is the best. The reasons for the phenomenon are simply that grading of HMAC-20 is better than those of HMAC-16 and HMAC-25, and additives for 




(a) Static modulus of HMAC-16

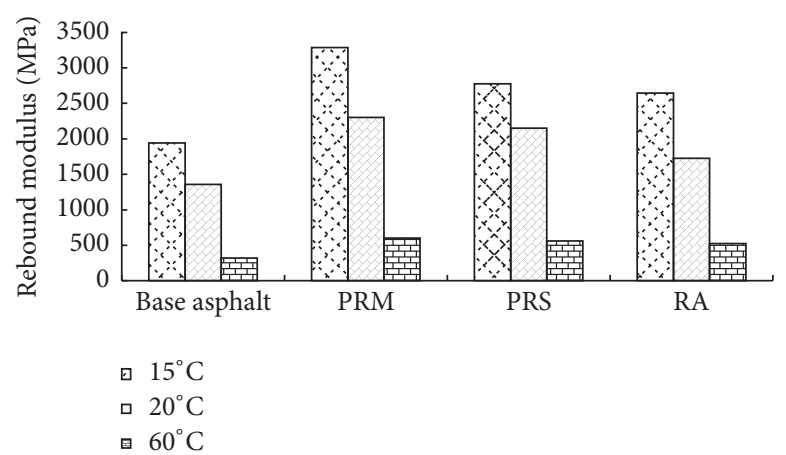

(b) Static modulus of HMAC-20

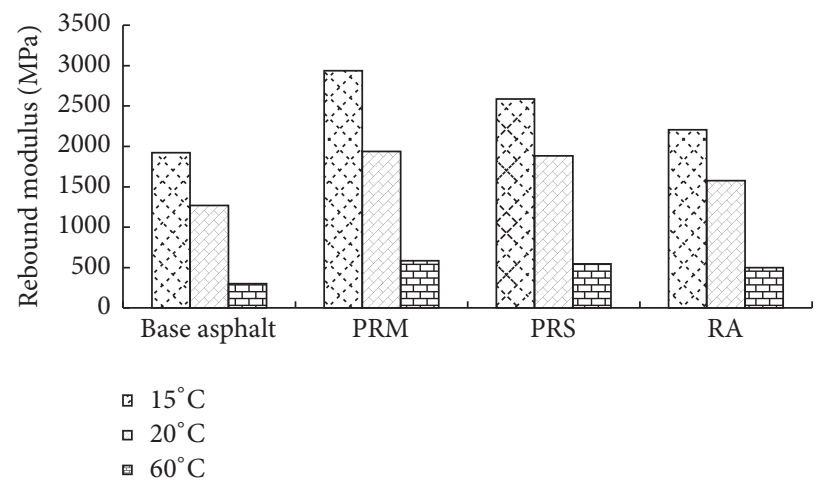

(c) Static modulus of HMAC-25

FigURE 4

TABle 6: Technical index of static modulus.

\begin{tabular}{lccc}
\hline \multirow{2}{*}{ Mixture } & \multicolumn{3}{c}{ Compressive modulus $(\mathrm{MPa})$} \\
& $15^{\circ} \mathrm{C}$ & $20^{\circ} \mathrm{C}$ & $60^{\circ} \mathrm{C}$ \\
\hline HMAC-16, HMAC-20 & $2600 \sim 3000$ & $2000 \sim 2400$ & $450 \sim 650$ \\
HMAC-25 & $2300 \sim 2700$ & $1800 \sim 2200$ & $400 \sim 600$ \\
\hline
\end{tabular}

improving modulus of HMAC-20 are better than those for HMAC-16 and HMAC-25.

In conclusion, the recommended common values of static modulus used as a reference for road design are shown in Table 6.

3.1.2. Dynamic Modulus. As a typical viscoelastic material, mechanical characteristics of asphalt mixture are closely related to loading frequency and temperature. Modulus and stiffness of the asphalt mixture decreased when loading rate decreased or temperature was risen, which are shown in Figures 5(a)-5(d) and Table 7.

Growth rate of dynamic modulus was larger when the frequency increased from $0.01 \mathrm{~Hz}$ to $2 \mathrm{~Hz}$ and it gradually reduced when the frequency increased from $2 \mathrm{~Hz}$ to $25 \mathrm{~Hz}$. In addition, the dynamic modulus of HMAC was bigger than that of conventional mixture regardless of frequency and temperature condition.

(1) A high frequency of loading was initially applied on HMAC in dynamic modulus test and then applied with low frequency loading. As seen in Figure 5, the dynamic modulus of asphalt mixture increases along with the increase of loading frequency. This is due to the fact that asphalt mixture is a typical viscoelastic material and mechanical properties related to the loading speed, material strength, and stiffness increased with the increase of loading rate. Asphalt mixture will not be instantaneously compressed under dynamic loading, nor will it be completely spring back after unloading. Mechanical properties of asphalt mixtures are as follows: strength and modulus under dynamic loading are bigger than those under static load. With the increase of loading frequency, the load response lag phenomenon is more obvious, indicating the strength and modulus of asphalt mixture increase with the increase of loading frequency.

(2) As shown in Figure 5, the dynamic modulus of asphalt mixture sharply increased at frequency ranging from 0.01 to $2 \mathrm{~Hz}$, and the increasing trend reduced ranging from 2 to $25 \mathrm{~Hz}$. This is because, at high load frequency, asphalt mixture is mainly characterized by elasticity; the influence of frequency on dynamic modulus is less than that of material property.

With dynamic loading at high and low frequencies, moduli of high modulus asphalt concrete are much bigger than those of common asphalt mixture. It is well known that the mechanical properties are better with higher modulus, meaning that high modulus additives can effectively improve the mechanical properties of asphalt mixture.

The mechanical properties of asphalt mixture are significantly correlated with loading rate, and loading frequency of $10 \mathrm{~Hz}$ is equivalent to the driving speed of $72 \sim 80 \mathrm{~km} / \mathrm{h}$ that 


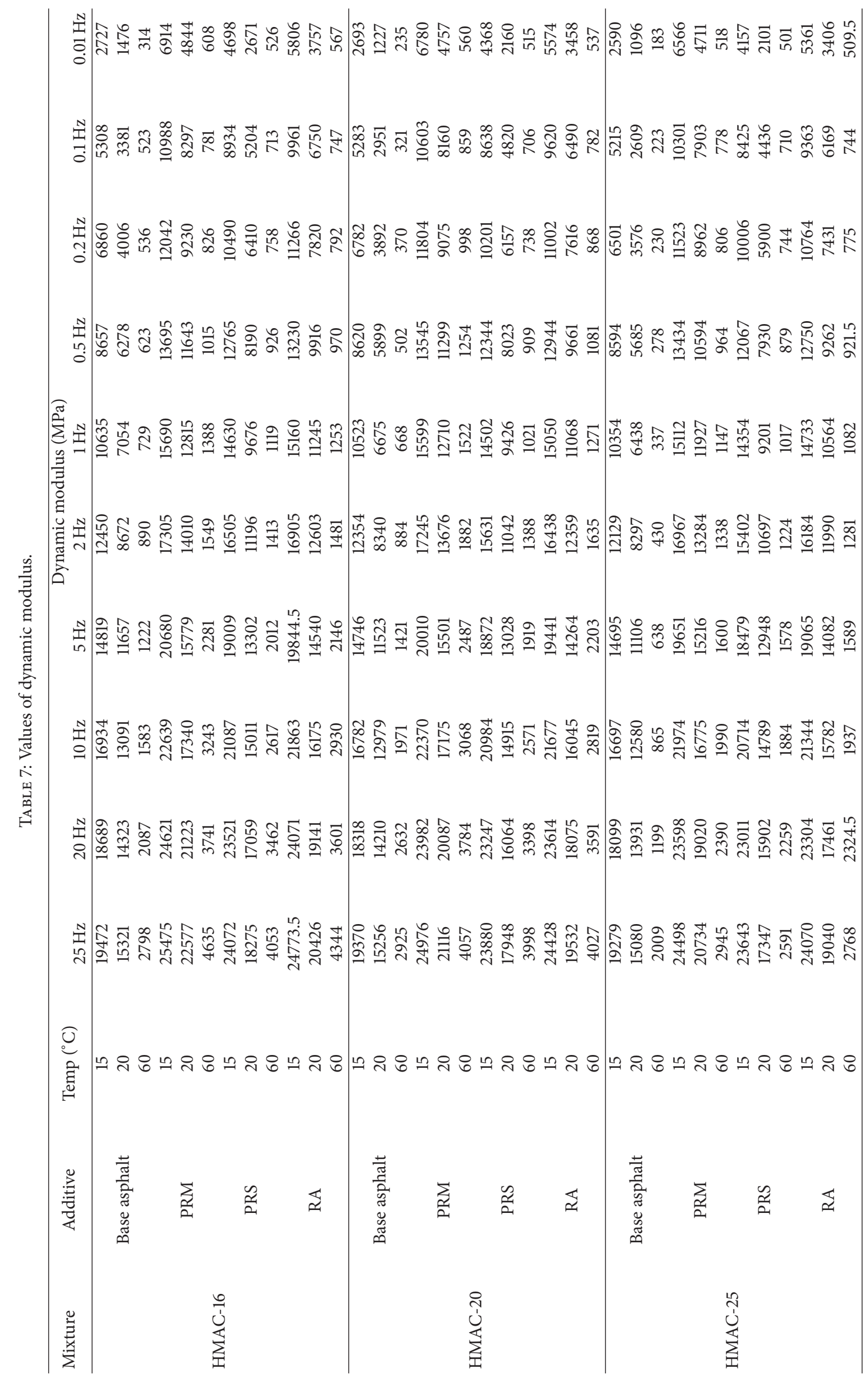




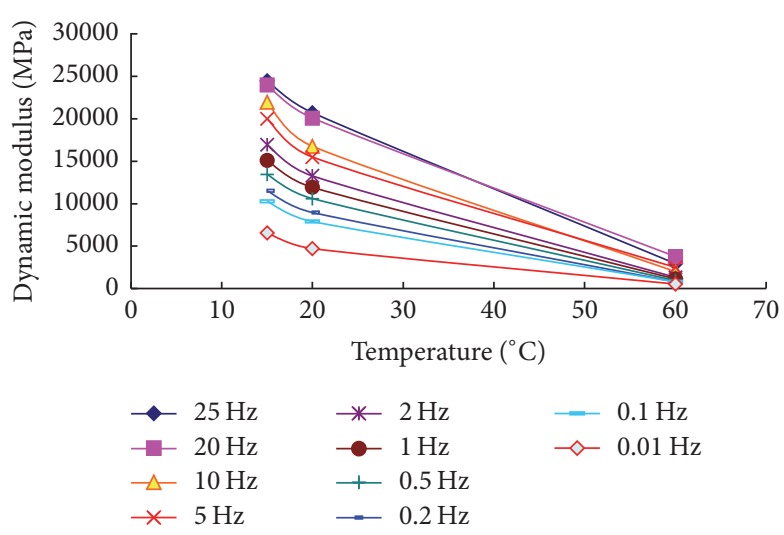

(a) Dynamic modulus of HMAC-PRM

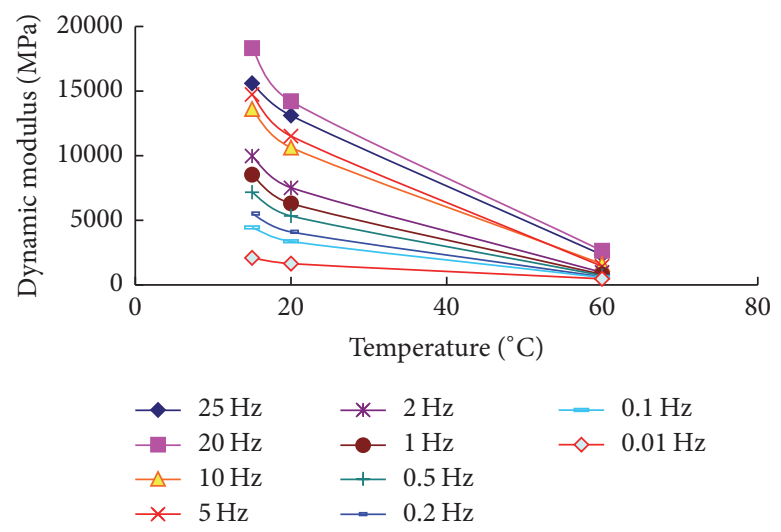

(c) Dynamic modulus of HMAC-RA

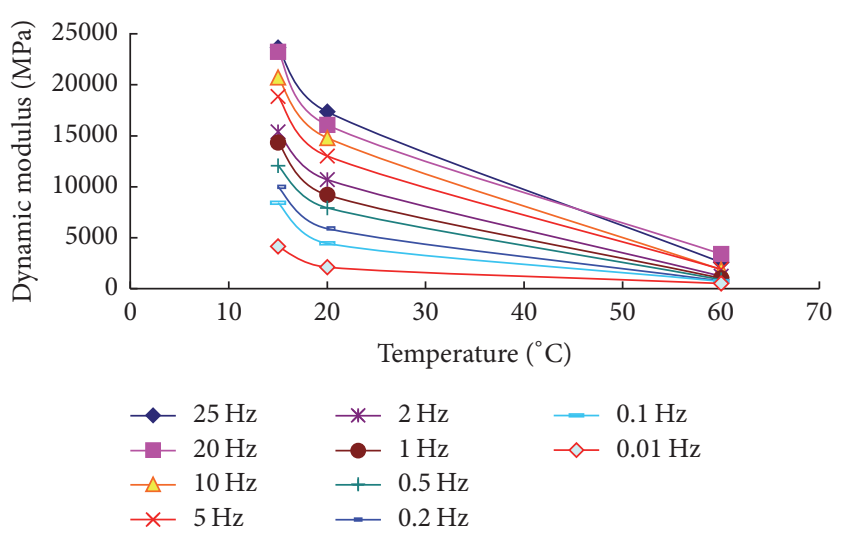

(b) Dynamic modulus of HMAC-PRS

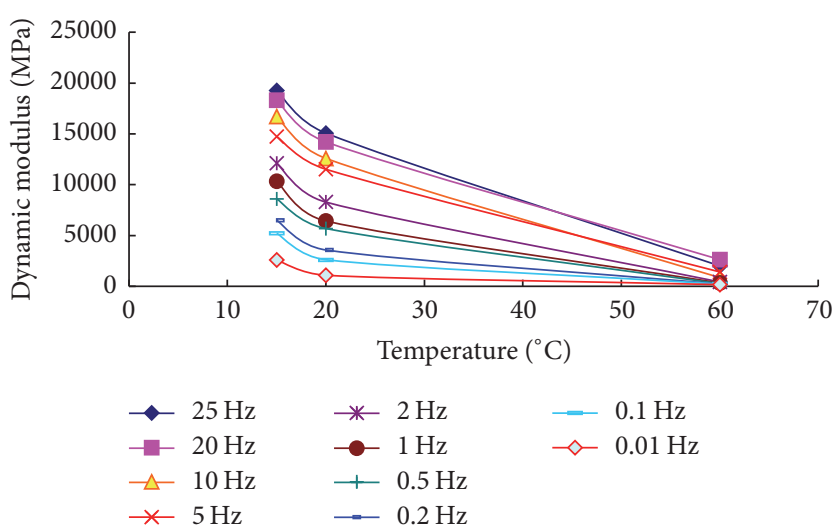

(d) Dynamic modulus of conventional mixture

Figure 5

is close to the normal speed. Therefore, dynamic modulus of HMAC at frequency of $10 \mathrm{~Hz}$ was systematically analyzed as shown in Figures 6(a)-6(c) [17], and then the corresponding evaluation index was put forward.

As shown in Figure 6, the dynamic modulus of asphalt mixture decreases along with the rise of temperature, and this is mainly because asphalt mixture is sensitive to temperature. When the temperature is higher, asphalt characteristics become physically soft, with strength and stiffness decreasing; thus dynamic modulus decreases. Under the low temperature and high temperature conditions, the dynamic modulus of high modulus asphalt concrete is far greater than that of the ordinary asphalt mixture.

At the frequency of $10 \mathrm{~Hz}$, dynamic modulus of HMAC decreased by $26 \%$ from $15^{\circ} \mathrm{C}$ to $20^{\circ} \mathrm{C}$ and $91 \%$ from $20^{\circ} \mathrm{C}$ to $60^{\circ} \mathrm{C}$, respectively. At the temperature of $60^{\circ} \mathrm{C}$, decreasing tendency of HMAC-25 was more striking than that of HMAC-20, which means dynamic modulus of HMAC-20 is superior to that of HMAC-25.

Based on analysis of the above test results and relevant analysis, common values of dynamic modulus were recommended which can be used as road design reference, as shown in Table 8.

3.1.3. Correlation between Dynamic Modulus and Static Modulus of HMAC. In this study, correlations between dynamic modulus and static modulus of high modulus asphalt mixture were studied to obtain approximate value of dynamic modulus from static modulus. At the frequency of $10 \mathrm{~Hz}$, comparative analyses of the dynamic modulus and static modulus of high modulus asphalt mixture (PRS) are shown in Figures $7(\mathrm{a})-7(\mathrm{c})$.

At frequency of $10 \mathrm{~Hz}$, the dynamic moduli at 15, 20, and $60^{\circ} \mathrm{C}$ are $8 \sim 10,8 \sim 10$, and $1.5 \sim 2.5$ times as much as static modulus, respectively. This phenomenon shows that dynamic modulus of asphalt mixture is far higher than the static modulus at normal temperature; however, change range of dynamic modulus is less than that of static modulus at high temperature. The mechanical properties of asphalt mixture are mainly viscous when test temperature increases or frequency decreases, whereas the mechanical properties are mainly elastic when teat temperature decreases or frequency increases.

As seen from Figures 7(a)-7(c), dynamic modulus was correlated with static modulus and correlation coefficient $\left(R^{2}\right)$ of HMAC-16, HMAC-20, and HMAC-25 was 0.9735 , 0.9735 , and 0.9702 , respectively, meaning that dynamic modulus of HMAC can be obtained from static modulus.

\subsection{High Temperature Performance Evaluation}

3.2.1. The Evaluation Standard for Dynamic Stability. Conformed to actual response of the pavement, wheel tracking test $\left(60^{\circ} \mathrm{C}, 0.7 \mathrm{MPa}\right)$ can reflect the change process of 


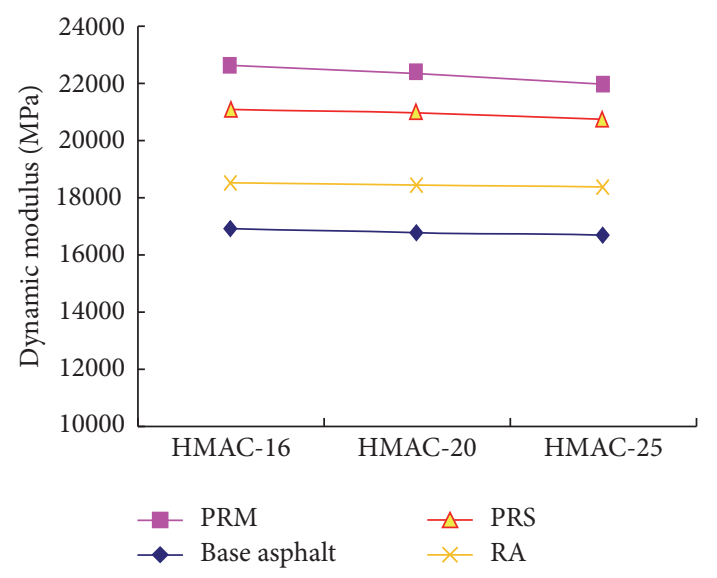

(a) Dynamic modulus of mixtures at $15^{\circ} \mathrm{C}$

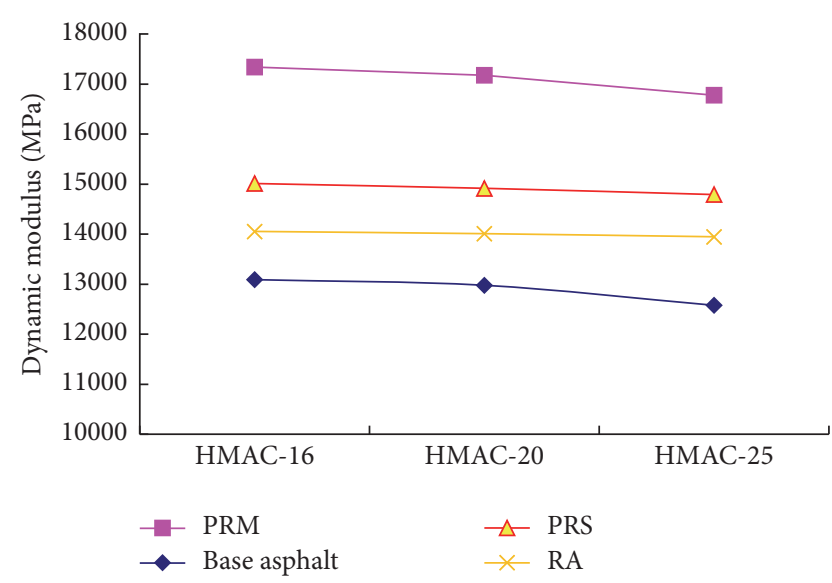

(b) Dynamic modulus of mixtures at $20^{\circ} \mathrm{C}$

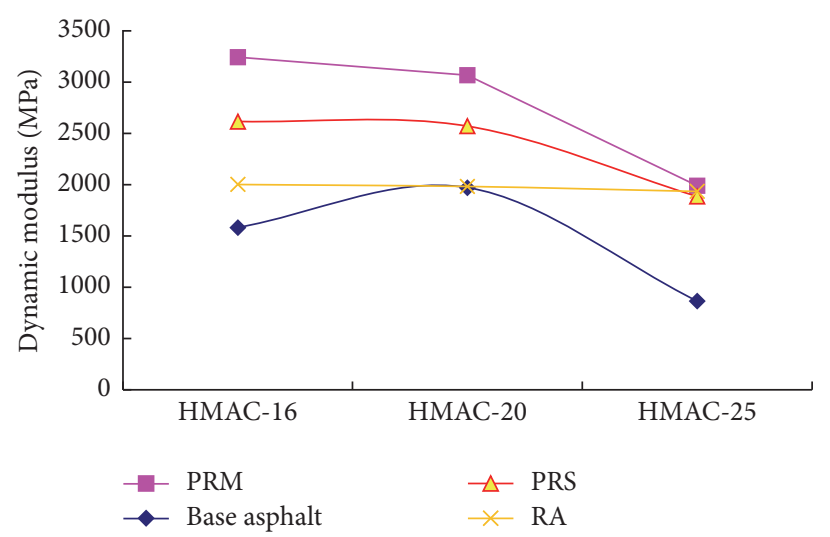

(c) Dynamic modulus of mixtures at $60^{\circ} \mathrm{C}$

Figure 6

TABLE 8: Common values of dynamic modulus at $10 \mathrm{~Hz}$.

\begin{tabular}{lccr}
\hline Mixture & & Dynamic modulus $(\mathrm{MPa})$ & \\
& $15^{\circ} \mathrm{C}$ & $20^{\circ} \mathrm{C}$ & $60^{\circ} \mathrm{C}$ \\
\hline HMAC-16, HMAC-20 & $18000 \sim 23000$ & $14000 \sim 18000$ & $2600 \sim 3200$ \\
HMAC-25 & $16000 \sim 20000$ & $14000 \sim 16000$ & $1800 \sim 2400$ \\
\hline
\end{tabular}

permanent deformation. Figures 8(a)-8(c) show the wheel tracking test results (dynamic stability, relative deformation parameters, and comprehensive stability index [18]) for the conventional asphalt mixture and HMAC.

As seen from Figures 8(a)-8(c), dynamic stability and complex stability index of HMAC were bigger than those of conventional mix. Meanwhile, relative deformation of HMAC was much smaller than that of conventional mixture, which means that HMAC is a fine pavement material with good high temperature performance. Moreover, dynamic stability of HMAC-20 and HMAC-25 was larger than that of HMAC-16.

(1) Dynamic stability of high modulus asphalt concrete (PRM, PRS, and RA) has greatly improved, far larger than that of matrix asphalt mixture, almost 3 4 times that of ordinary asphalt mixture; dynamic stability of HMAC (RA) has also improved, but the improving effect is less obvious than those of high modulus asphalt concrete (PRM, PRS).

(2) Similarly, the comprehensive stability index of high modulus asphalt concrete (PRM, PRS, and RA) is also greatly improved compared with ordinary asphalt mixture. However, the improving effect of RA is not obvious as that of high modulus asphalt concrete (PRM, PRS).

(3) Relative deformation of matrix asphalt mixture and RA mixture is much larger than that of high modulus asphalt concrete (PRM, PRS), and the relative deformation of matrix asphalt mixture is basically the same as that of RA mixture.

(4) Dynamic stability of HMAC-20 and HMAC-25 is greater than that of HMAC-16, whereas comprehensive stability index is smaller than that of HMAC-16, suggesting that rutting resistance of HMAC-25 and HMAC-20 is better than that of HMAC-16. 


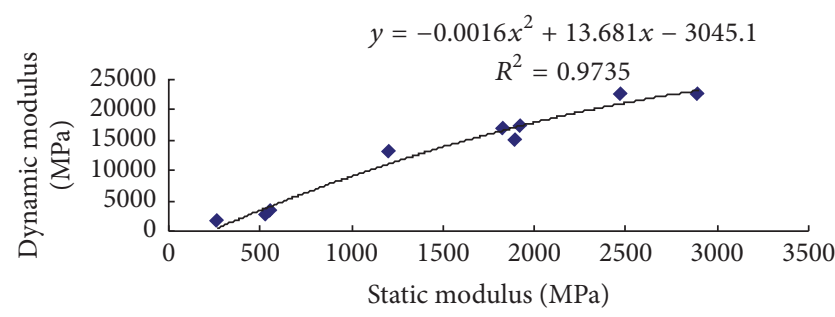

(a) Correlation between dynamic and static modulus of HMAC-16



(b) Correlation between dynamic and static modulus of HMAC-20

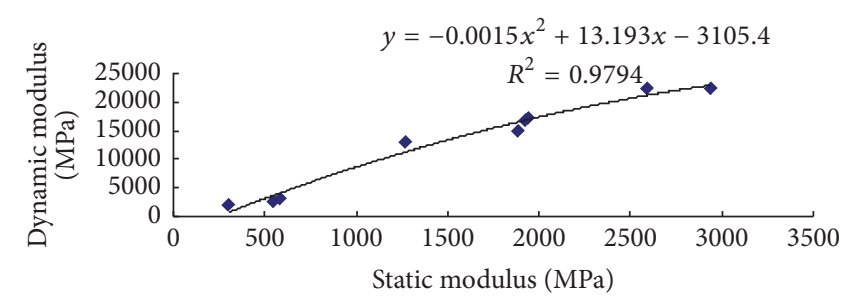

(c) Correlation between dynamic and static modulus of HMAC-25

Figure 7



(a) Dynamic stability of HMAC with different additives

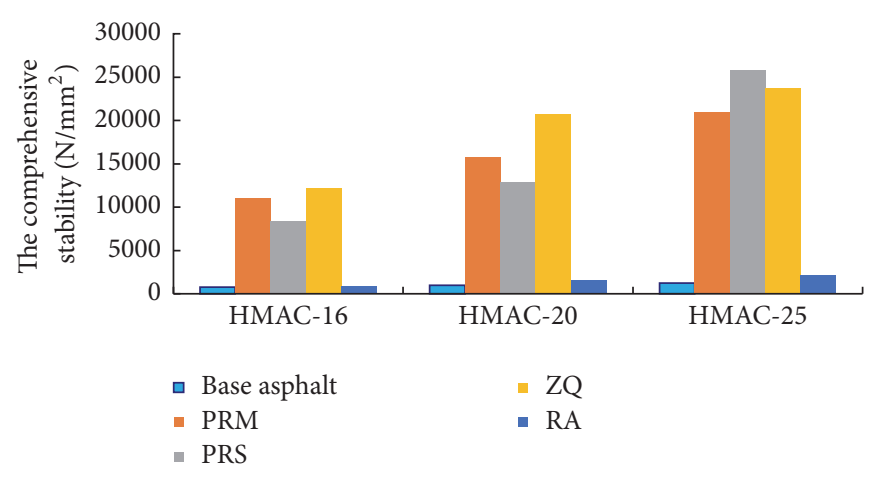

(c) Comprehensive stability index of HMAC with different additives
To sum up, high modulus asphalt concrete has better dynamic stability, with larger comprehensive stability index and smaller relative deformation, indicating that HMAC has good rutting resistance at high temperature. This is mainly because both asphalt and mixture are modified by additives. Shearing force of dry mixed aggregate will make

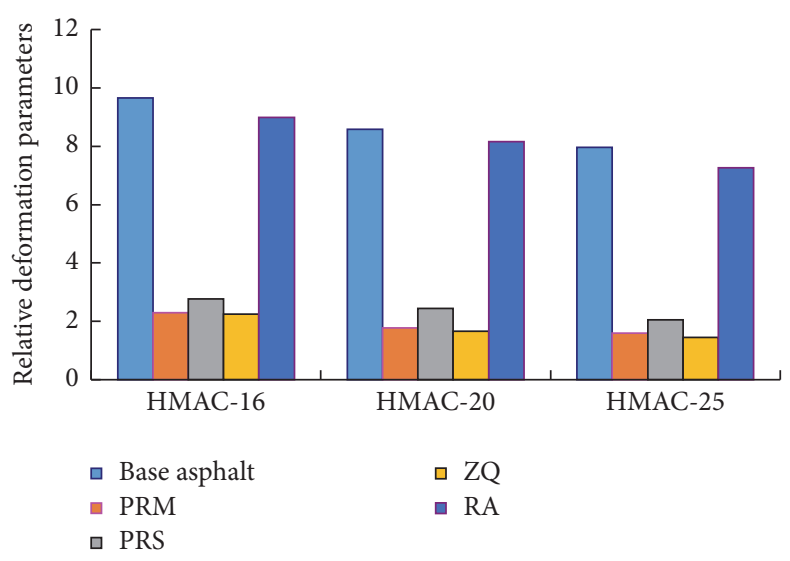

(b) Elative deformation parameters of HMAC with different additives

Figure 8

high modulus additives dispersed evenly in the mixture, mechanical embedded crowded, reinforced, and cemented, and road performance improved. The improvement effect is more obvious with the increase of dosage.

In addition, dynamic stability and the comprehensive stability index of HMAC (HMAC-20, HMAC-25) are bigger 




(a) Shear strength at $15^{\circ} \mathrm{C}$

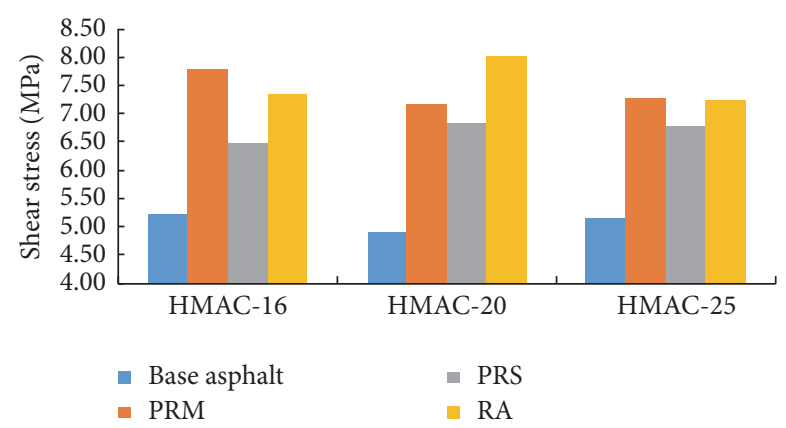

(b) Shear strength at $20^{\circ} \mathrm{C}$

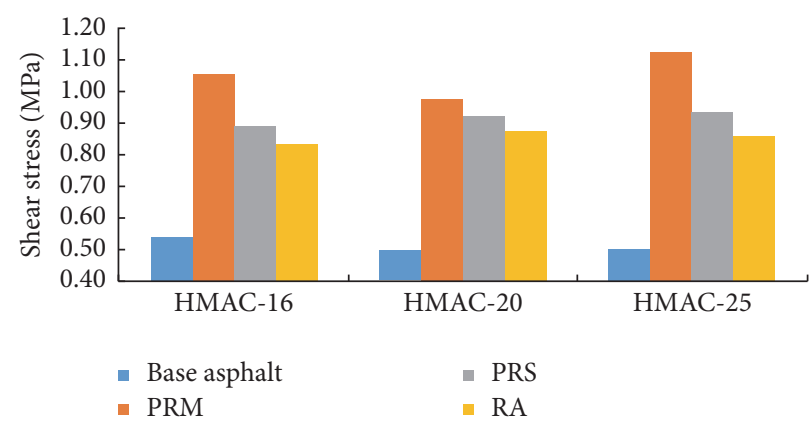

(c) Shear strength at $60^{\circ} \mathrm{C}$

Figure 9

than those of HMAC-16, whereas relative deformation is much smaller than that of HMAC-16, concluding that proposed gradation design for HMAC-20 and HMAC- 25 can improve the high temperature rutting resistance of asphalt mixture.

Combined with the experimental results, HMAC common values for dynamic stability $(\geq 8000 \mathrm{~N} / \mathrm{mm})$ are recommended.

3.2.2. Shear Strength Evaluation Standard. Shear strengths of mixture with different additives were determined at three different temperatures $\left(15,20\right.$, and $\left.60^{\circ} \mathrm{C}\right)$, as shown in Figures 9(a) -9 (c).

Shear strengths of specimen with additives increased by $19 \%, 51 \%$, and $67 \%$ at 15,20 , and $60^{\circ} \mathrm{C}$ compared to conventional mixture without additives, which means additives can improve the shear behavior of asphalt mixture.

What is more, shear strengths decrease with the increase of temperature. Shear strengths of specimen with additives increased by $15 \% \sim 23 \%, 38 \% \sim 64 \%$, and $76 \% \sim 97 \%$ at 15 , 20 , and $60^{\circ} \mathrm{C}$ compared to conventional mixture without additives, suggesting that the higher the temperature, the larger the shear strength.

Figures 9(a)-9(c) also show that shear strengths among HMAC-16, HMAC-20, and HMAC-25 are almost the same, which means that nominal maximum aggregate size has limited influences on shear behavior of HMAC.

Combined with performance index of dense gradation mixture, uniaxial shear test at $60^{\circ} \mathrm{C}$ was recommended to evaluate the shear behavior of HMAC and the common values for shear behavior at different temperatures $(15,20$, and $60^{\circ} \mathrm{C}$ ) were proposed as shown in Table 9.
TABLE 9: Common values of shear strength.

\begin{tabular}{lc}
\hline Temperature & Shear strength $(\mathrm{MPa})$ \\
\hline $15^{\circ} \mathrm{C}$ & $7.5 \sim 9.0$ \\
$20^{\circ} \mathrm{C}$ & $5.5 \sim 7.0$ \\
$60^{\circ} \mathrm{C}$ & $0.8 \sim 1.2$ \\
\hline
\end{tabular}

3.3. Low Temperature Performance Evaluation. As can be seen from Figure 10, maximum bending strain of HMAC-16 is greater than those of HMAC-20 and HMAC-25, suggesting that nominal maximum aggregate size has evident influences on low temperature performance. Effects of additive dosage on low temperature performance are shown in Figure 11.

Figure 12 shows that the maximum failure strain of HMAC decreased when dosage of additive increased. Maximum failure strain decreased by $34.9 \%$ when the percentage of PRS was $0.8 \%$ (mass ratio between PRS and mixture) and it decreased by $25.4 \%$ when the percentages of RA was $0.8 \%$ (mass ratio between RA and mixture), which means that modifier of mixture can reduce the low temperature crack resistance. Thus, dosage or type of the modifier can be chosen based on high temperature stability, and low temperature anticracking performance can just meet the basic requirements.

It is hard to take both high and low temperature performance of asphalt mixture into account. Therefore, performance of modified asphalt mixture should be examined according to the modifying purpose, meaning that the low temperature performance can just meet conventional standard as the main modifying purpose is to improve the high temperature performance. 


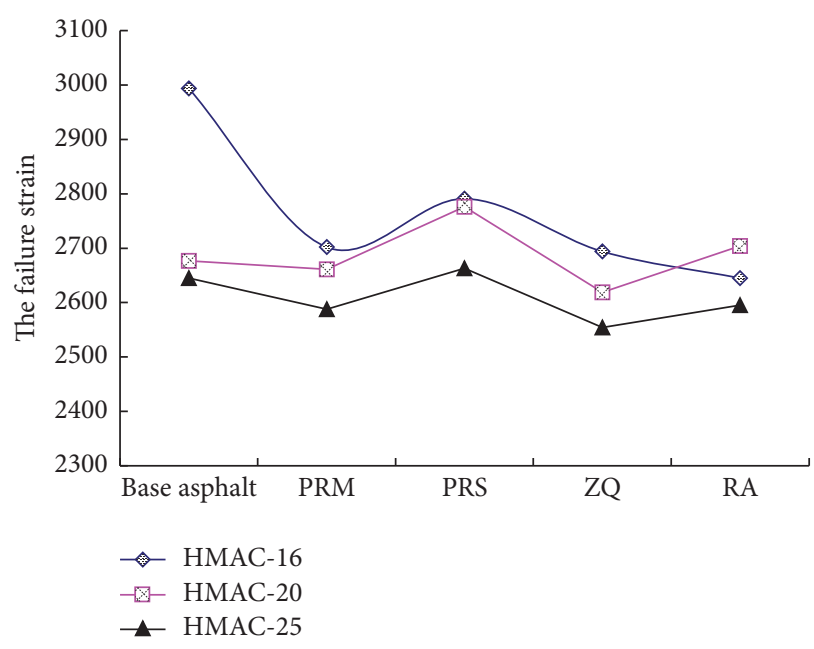

FIGURE 10: The maximum flexure tensile strain of asphalt mixture.



FIGURE 11: The maximum flexure tensile strain of asphalt mixture with different dosage of additive.

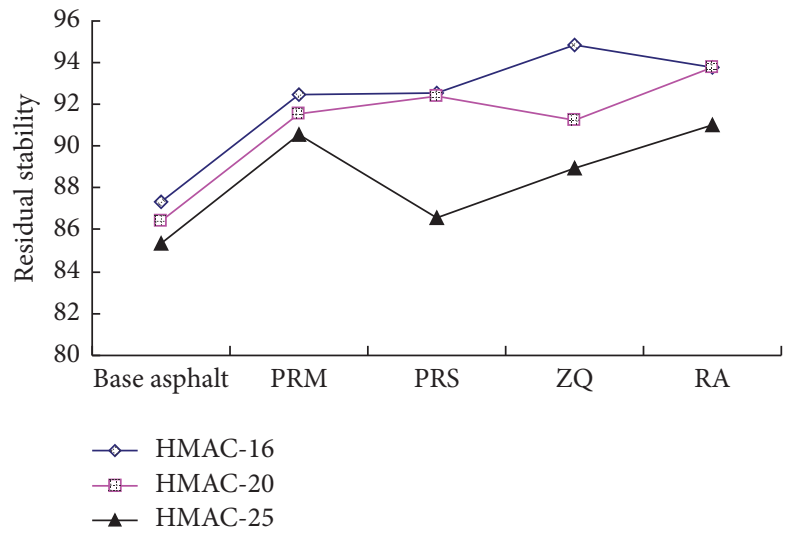

FIGURE 12: Residual stability of HMAC.

3.4. Water Stability Evaluation. Results for immersing Marshall test and freeze-thaw splitting strength are shown in Figures 12 and 13. The change trend of residual stability was in accordance with that of freeze-thaw split intensity ratio.
The ranking among the three mixes is HMAC-16, HMAC20 , and HMAC-25 from superior to inferior. HMAC-16 with optimum asphalt content produced larger mineral aggregate surface with the increasing of interacted aggregate superficial 


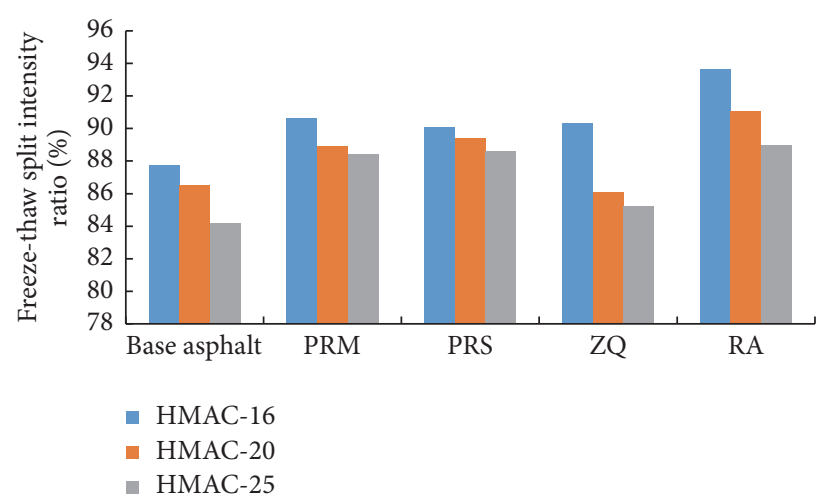

FIGURE 13: Freeze-thaw split intensity ratio of HMAC.

TABLE 10: Comprehensive evaluating system of HMAC performance.

\begin{tabular}{|c|c|c|c|c|}
\hline Evaluation index & \multicolumn{2}{|c|}{ HMAC-16, HMAC-20 } & HMAC-25 & Test methods \\
\hline \multirow[t]{2}{*}{ Dynamic stability $(\mathrm{N} / \mathrm{mm})$} & $\geq 8000$ & & $\geq 8000$ & JTJ T0719 \\
\hline & $15^{\circ} \mathrm{C}$ & $7.5 \sim 9.0$ & $7.5 \sim 9.0$ & \\
\hline \multirow[t]{3}{*}{ Shear strength $(\mathrm{MPa})$} & $20^{\circ} \mathrm{C}$ & $5.5 \sim 7.0$ & $5.5 \sim 7.0$ & JTGE40-2007-T0134 \\
\hline & $60^{\circ} \mathrm{C}$ & $0.8 \sim 1.2$ & $0.8 \sim 1.2$ & \\
\hline & $15^{\circ} \mathrm{C}$ & $2600 \sim 3000$ & $2300 \sim 2700$ & \\
\hline \multirow[t]{3}{*}{ Static modulus (MPa) } & $20^{\circ} \mathrm{C}$ & $2000 \sim 2400$ & $1800 \sim 2200$ & ASTM D1074 (rate of $2 \mathrm{~mm} / \mathrm{min}$ ) \\
\hline & $60^{\circ} \mathrm{C}$ & $450 \sim 650$ & $400 \sim 600$ & \\
\hline & $15^{\circ} \mathrm{C}$ & $18000 \sim 23000$ & $16000 \sim 20000$ & \\
\hline \multirow[t]{2}{*}{ Dynamic modulus (MPa) } & $20^{\circ} \mathrm{C}$ & $14000 \sim 18000$ & $14000 \sim 16000$ & AASHTO TP 62-03 \\
\hline & $60^{\circ} \mathrm{C}$ & $2600 \sim 3200$ & $1800 \sim 2400$ & \\
\hline
\end{tabular}

area. Moreover, cohesion of HMAC-16 was higher than those of HMAC-25 and HMAC-20, which means that HMAC-16 has better water stability.

It is believed that the following factors were important and potential to impact water stability of HMAC: (1) additives of asphalt mixture (PRS, PRM, ZQ, and RA); (2) skeleton dense structure of the mixture gradations; (3) alkaline aggregate (limestone). The main purpose of HMAC is to improve the high temperature stability. Thus, there are no special requirements for water stability as long as it meets the standard for conventional mixture.

3.5. HMAC Performance Evaluation System. On the basis of the experimental results and relevant specifications, the HMAC performance evaluation system was put forward as shown in Table 10. Rutting test at the $60^{\circ} \mathrm{C}$ of temperature is adopted to evaluate high temperature performance, the uniaxial penetration test is adopted to evaluate the shear performance, modulus test is adopted to evaluate the dynamic and static modulus, low temperature bending test is adopted to evaluate low temperature performance, and water stability test is adopted to evaluate retained Marshall stability and freeze-thaw split intensity ratio. On the whole, high temperature performance, shear performance, and modulus refer to evaluation system of HMAC (high modulus asphalt concrete) performance, technical indexes of low temperature performance adopt conventional asphalt mixture standard, and water stability adopts modified bitumen mixture standard $[19,20]$.

\section{Conclusions}

This study provides an experimental investigation on the performance of high modulus asphalt concrete, including the uniaxial compression test, simple performance tests (SPT), wheel tracking test, the uniaxial penetration test, the bending test, freeze-thaw splitting strength test, and immersion Marshall test $[21,22]$. The tests were performed on HMAC16, HMAC-20, and HMAC-25 and the following conclusions can be drawn:

(1) The uniaxial compression results show that temperature has significant effects on static modulus and it is significant at higher temperature. Moreover, modulus of HMAC-20 is superior to those of HMAC-16 and HMAC-25.

(2) The dynamic modulus $\left(E^{*}\right)$ results show that dynamic modulus of HMAC is larger than that of conventional asphalt mixture regardless of load frequency and temperature.

(3) Wheel tracking test shows that high temperature performance of HMAC is better than that of conventional mixture and high temperature performance of HMAC-25 and HMAC-20 is superior to that of HMAC-16. Common values of HMAC dynamic stability $(\geq 8000 \mathrm{~N} / \mathrm{mm})$ are recommended, and correlation between dynamic modulus and static modulus of HMAC is proposed combined with the 
effect of different modifier contents on the dynamic stability of HMAC.

(4) Low temperature anticracking performance and water stability do not need special requirements as long as they meet the specification.

(5) Nominal maximum aggregate size has limited influence on shear behavior of HMAC. Uniaxial shear test is recommended to evaluate the shear behavior of HMAC and the common values of HMAC shear behavior are proposed.

(6) The common values of HMAC performance are proposed based on pavement performance tests. It is expected that further analysis of more samples will be significant in evaluation system of HMAC performance.

\section{Conflicts of Interest}

The authors declare no conflicts of interest.

\section{Acknowledgments}

This research was supported by the Transportation Department of Shandong Province (Grant no. 2008Y007), the Fundamental Research Funds for the Central Universities (Grant no. 310821163502), the Transportation Department of Hebei Province (Grant nos. T-2012107, Y-2012014), the National Natural Science Foundation (Grant no. 51008033), and the Transportation Department of Hubei Province of China (Grant no. Ejiaokejiao [2013] 731).

\section{References}

[1] B. Shackel, "The objective selection of concrete block paving for engineering projects," in Proceedings of the 8th International Conference on Concrete Block Paving, San Francisco, Calif, USA, November, 2006.

[2] L. Petho, "High modulus asphalt mix (EME) for heavy duty applications and preliminary laboratory test results in Australia," in Proceedings of the AAPA 15th International Flexible Pavements Conference, Brisbane, Australia, 2013.

[3] H. J. Lee, J. H. Lee, and H. M. Park, "Performance evaluation of high modulus asphalt mixtures for long life asphalt pavements," Construction and Building Materials, vol. 21, no. 5, pp. 10791087, 2007.

[4] H. Geng, C. S. Clopotel, and H. U. Bahia, "Effects of high modulus asphalt binders on performance of typical asphalt pavement structures," Construction and Building Materials, vol. 44, pp. 207-213, 2013.

[5] M. Espersson, "Effect in the high modulus asphalt concrete with the temperature," Construction and Building Materials, vol. 71, pp. 638-643, 2014.

[6] R. Ghabchi, D. Singh, and M. Zaman, "Laboratory evaluation of stiffness, low-temperature cracking, rutting, moisture damage, and fatigue performance of WMA mixes," Road Materials and Pavement Design, vol. 16, no. 2, pp. 334-357, 2015.

[7] C. Han, F.-W. An, and W.-J. Wei, "Concerted design of hard paving grade asphalt high modulus mixture based on the aggregate image measurement system," in In Proceedings of the New Frontiers in Road and Airport Engineering, pp. 50-63.
[8] C. Wu, B. Jing, and X. Li, "Performance evaluation of highmodulus asphalt mixture," Advanced Materials Research, vol. 311-313, pp. 2138-2141, 2011.

[9] Y. Sun and L. Li, “Testing and evaluating fatigue performance of high-modulus asphalt," in Proceedings of the 14th COTA International Conference of Transportation Professionals: Safe, Smart, and Sustainable Multimodal Transportation Systems, (CICTP '14), pp. 1091-1100, July 2014.

[10] M. Zheng, "Viscoelastic parameters of high modulus asphalt concrete and permanent deformation numerical simulation," Journal of Materials in Civil Engineering, vol. 28, no. 7, Article ID 04016020, 2016.

[11] Transportation Research Board TRB, "Simple performance test for superpave mix design,” NCHRP Report, 2002.

[12] F. Moreno-Navarro, M. Sol-Sánchez, M. C. Rubio-Gámez, and M. Segarra-Martínez, "The use of additives for the improvement of the mechanical behavior of high modulus asphalt mixes," Construction and Building Materials, vol. 70, pp. 65-70, 2014.

[13] K. Kaloush, Simple performance test for permanent deformations of asphalt mixtures [Dissertation], Arizona State University, 2001.

[14] AASHTO, "Mechanistic-empirical pavement design guide. a manual of practice," in Proceedings of the American Association of State Highway and Transportation Officials (AASHTO '08), Washington DC, USA, July 2008.

[15] M. Zheng, L. Han, F. Wang, H. Mi, Y. Li, and L. He, "Comparison and analysis on heat reflective coating for asphalt pavement based on cooling effect and anti-skid performance," Construction and Building Materials, vol. 93, pp. 1197-1205, 2015.

[16] AASHTO T 209-05, “Theoretical maximum specific gravity and density of hot mix paving mixtures, 27 th ed., standard specifications for transportation materials and methods of sampling and testing," in AASHTO, Washington, DC, USA, 27th edition, 2007.

[17] S. Andrea, P. Matteo, S. Cesare, and R.-Z. Wu, "Performance evaluation of eco-friendly asphalt concretes using the simple shear and $4 \mathrm{p}$ bending tests," in Proceedings of the SIIV-5th International Congress-Sustainability of Road Infrastructures, vol. 53, pp. 410-420.

[18] A. S. M. Rahman, H. M. Faisal, and R. A. Tarefder, "Changes in viscoelastic characteristics of asphalt concrete and binder due to aging, in: 94th," in Proceedings of the Transportation Research Board (TRB) Annual Meeting, pp. 11-15, January 2015.

[19] A. Benta, C. Duarte, A. Almeida-Costa, T. Cordeiro, and R. Pereira, "Design and performance of a warm high-modulus asphalt concrete," Journal of Cleaner Production, vol. 95, pp. 5565, 2015.

[20] Long Term Pavement Performance, "Test method for determining the creep compliance, resilient modulus and strength of asphalt material using the indirect tensile test device, Version 1.1, LTPP Test Protocol," FHWA; 2001.

[21] Corté J. F., "Development and uses of hard grade asphalt and of high modulus asphalt mixes in France," Transportation Research Circular 503, TRB, National Research Council, Washington, DC, USA, 2003.

[22] W. Bankowski, M. Tusar, and L. G. Wiman, "Laboratory and field implementation of high modulus asphalt concrete. Requirements for HMAC mix design and pavement design," in In Proceedings of the European Commission DG Research, 6th Framework Programme, Sustainable Surface Transport, Sustainable Pavements for European New Members States, SPENS, 2009. 

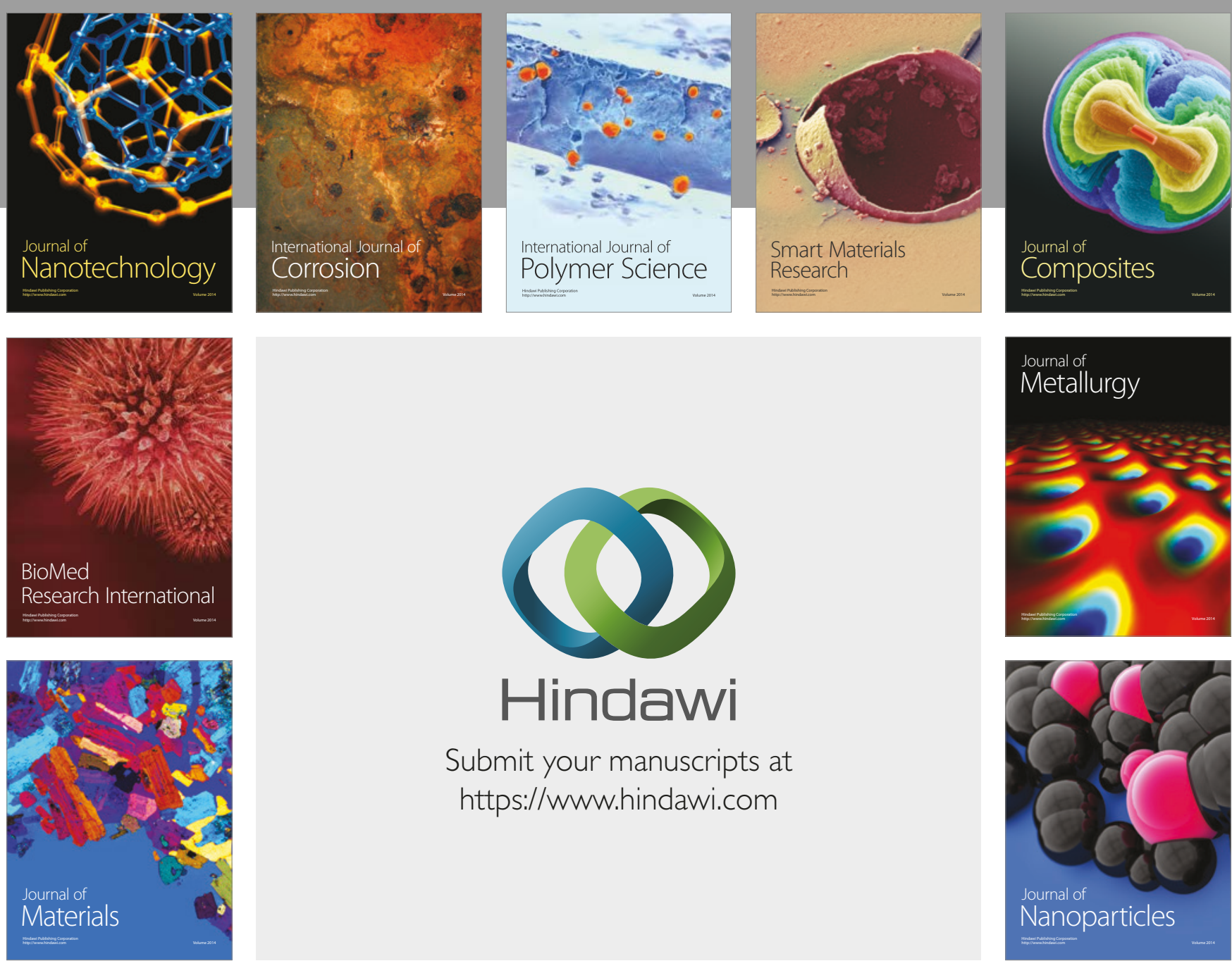

\section{Hindawi}

Submit your manuscripts at

https://www.hindawi.com
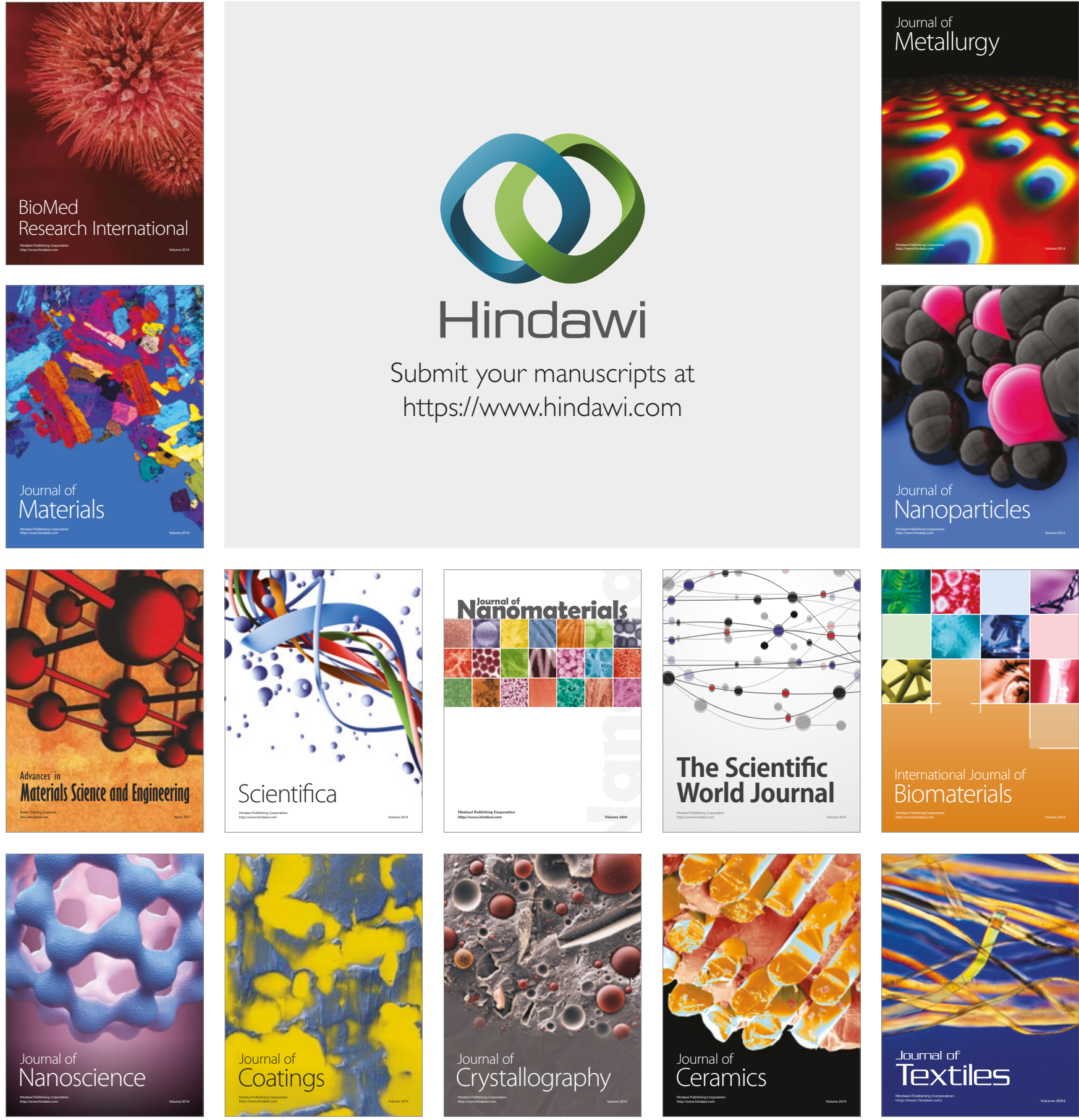

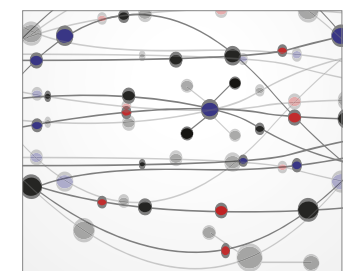

The Scientific World Journal
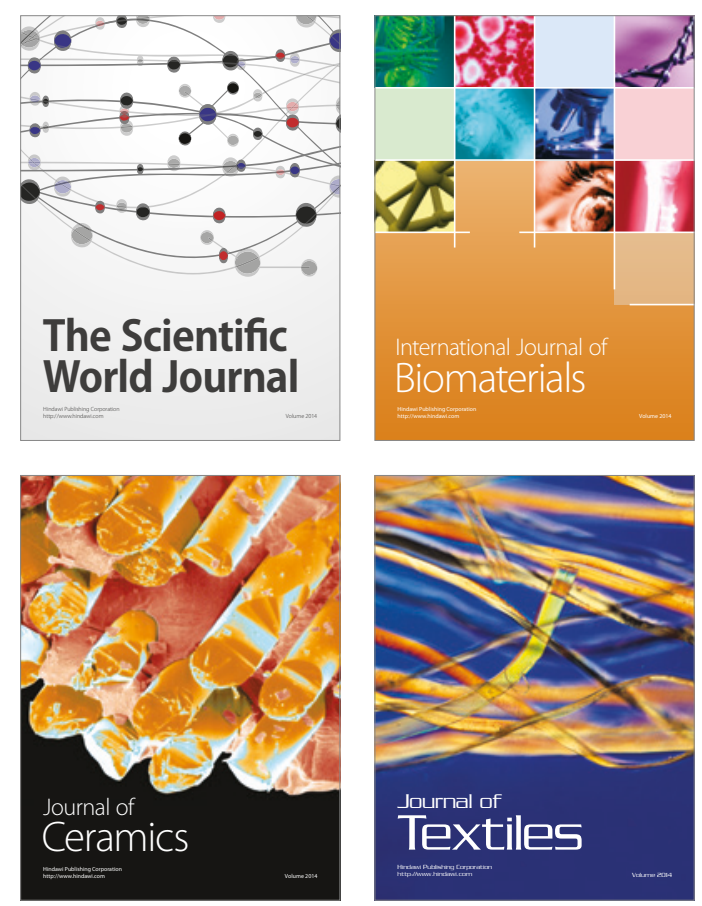